\title{
Progress in detecting cell-surface protein receptors: the erythropoietin receptor example
}

\author{
Steve Elliott • Angus Sinclair • Helen Collins • \\ Linda Rice • Wolfgang Jelkmann
}

Received: 1 October 2013 / Accepted: 2 November 2013 /Published online: 14 December 2013

(C) The Author(s) 2013. This article is published with open access at Springerlink.com

\begin{abstract}
Testing for the presence of specific cell-surface receptors (such as EGFR or HER2) on tumor cells is an integral part of cancer care in terms of treatment decisions and prognosis. Understanding the strengths and limitations of these tests is important because inaccurate results may occur if procedures designed to prevent false-negative or falsepositive outcomes are not employed. This review discusses tests commonly used to identify and characterize cell-surface receptors, such as the erythropoietin receptor (EpoR). First, a summary is provided on the biology of the Epo/EpoR system, describing how EpoR is expressed on erythrocytic progenitors and precursors in the bone marrow where it mediates red blood cell production in response to Epo. Second, studies are described that investigated whether erythropoiesisstimulating agents could stimulate tumor progression in cancer patients and whether EpoR is expressed and functional on tumor cells or on endothelial cells. The methods used in these studies included immunohistochemistry, Northern blotting, Western blotting, and binding assays. This review summarizes the strengths and limitations of these methods. Critically analyzing data from tests for cell-surface receptors such as EpoR requires understanding the techniques utilized and
\end{abstract}

S. Elliott $\cdot$ A. Sinclair $(\triangle) \cdot$ H. Collins

Department of Hematology/Oncology, Amgen Inc., One Amgen

Center Drive, Mail Stop 15-2-A, Thousand Oaks, CA 91320, USA

e-mail: anguss@amgen.com

L. Rice

Department of Medical Writing, Amgen Inc., Thousand Oaks, CA, USA

W. Jelkmann

Institute of Physiology, University of Lübeck, Lübeck, Germany

Present Address:

H. Collins

Gilead Sciences, Inc., Foster City, CA, USA demonstrating that results are consistent with current knowledge about receptor biology.

Keywords Erythropoietin receptor · Erythropoiesis · Cancer · Angiogenesis · Antibody

\section{Introduction}

A current focus of oncology research is identifying tumorspecific antigens, such as cell-surface protein receptors. Therapeutic treatments have been developed to target some of these receptors, and receptor expression is sometimes used as a prognostic indicator. However, detecting the presence of a cell-surface receptor on tumor cells does not guarantee that inhibiting receptor activity will block tumor progression. For example, colorectal tumors overexpressing epidermal growth factor receptor (EGFR) respond to anti-EGFR antibody treatment only in the absence of mutations that constitutively activate $K R A S$ [1]. In contrast, overexpression of human epidermal growth factor receptor 2 (HER2) on breast-cancer cells is highly predictive of response to anti-HER2 antibody therapy [2]. Though cancer-treatment decisions and prognosis often depend on knowing whether a protein receptor is present, tests for detecting receptors can be unreliable. For example, inaccurate outcomes from HER2-immunohistochemical tests can occur due to issues with fixation, assay validation, equipment calibration, testing reagents, and interpretation criteria, leading to both false-positive and false-negative results [3, 4]. Because of the uncertainty of some HER2 laboratory testing procedures, guidelines were published to improve testing quality [5].

As new receptors are discovered and targeted therapies developed, a basic understanding of the strengths and limitations of methods for detecting, quantifying, and characterizing cell-surface receptors becomes increasingly important for 
cancer treatment/prognosis and for interpreting data. Amplified receptors can be identified by detecting increased genecopy number (via Southern blotting and fluorescence in situ hybridization [FISH]) or increased mRNA levels (via reverse transcriptase-polymerase chain reaction [RT-PCR], Northern blotting, or microarray) (Table 1). Increased receptor-protein levels can be detected in tissue sections (via immunohistochemistry [IHC]), in cell homogenates (via Western blotting), or on the surface of intact cells (via binding assays with labeled-receptor ligand or flow cytometry with specific antibodies). Evaluating the presence of functional protein involves examining if downstream signaling or enhanced growth/cell survival occurs after cell exposure to the receptor's ligand. Any single method requires adequate controls and confirmation of results to exclude false-positive and/or falsenegative outcomes.

To illustrate the strengths and limitations of various methods for detecting the presence, expression, and function of cell-surface protein receptors, we use examples from the literature regarding the cell-surface erythropoietin receptor (EpoR). Normally, EpoR is expressed on erythrocytic progenitors and precursors in bone marrow where it mediates red blood cell production in response to erythropoietin (Epo) produced by the kidneys (Fig. 1) [6]. Some clinical studies have suggested that patients with cancer treated with recombinant human Epo (rHuEpo) or other erythropoiesisstimulating agents (ESAs) have decreased loco-regional control of tumor growth and/or decreased survival [7]. Potentially explaining these observations, it has been hypothesized that ESAs could bind and activate EpoR on tumor cells to promote their growth and/or survival $[8,9]$ or stimulate EpoR on endothelial cells to promote tumor angiogenesis [10]. However, other reports indicate that EpoR is not required for normal development of organs or endothelium [11], there is no clinical progression of tumors in response to ESAs, that tumor and endothelial cells do not express functional EpoR, and that some methods of testing for EpoR have led to falsepositive results [6, 12-14].

This review summarizes techniques commonly used to identify cell-surface receptors in the context of the large quantity of published EpoR research. The most commonly used technique in clinical care, IHC, will be discussed. Since evaluating the strengths and limitations of other EpoR-detection methods requires background about normal EpoR and erythropoiesis, general information about EpoR biology will be briefly reviewed. Detailed information will then be presented on techniques used to examine specific aspects of EpoR expression, function, and hypothesized roles in tumor progression/angiogenesis. To identify articles for inclusion in this narrative review, several broad searches of the biologic and medical literature were carried out using the Ovid systems (Medline, EMBASE, and BIOSIS Previews).

\section{Immunohistochemical staining}

IHC is a widely used antibody-based test for detecting receptors, such as HER2, in tumors. IHC testing requires an antibody that specifically recognizes the receptor (Table 1). Tissue collection, fixation, and sectioning influence the ability of an antibody to bind a receptor [5]; thus, controls are essential to exclude false-negative and false-positive results. Further, interpretation of results requires training on understanding and quantifying outcomes (e.g., 0-3+ values in HER2 IHC reporting) [5].

Although published guidelines exist on validating and employing antibodies for IHC, these guidelines are not always followed [15]. With EpoR, many commercially available antiEpoR antibodies are nonspecific in that they bind to non-target proteins and other cell-matrix structures [16-18]. Notably, there are currently no anti-EpoR antibodies with the sensitivity and specificity to detect EpoR by IHC, yet there are dozens of IHC studies describing EpoR expression based on results with antibodies shown to be nonspecific [6]. For example, an association was earlier noted between staining intensities in head and neck tumor sections (stained with the "anti-EpoR" polyclonal antibody [C-20)] from Santa Cruz Biotechnology Inc.) and the clinical outcomes of the patients who were treated with ESAs [8]. However, several groups of investigators subsequently demonstrated that C-20 produces falsepositive signals because it binds to non-EpoR proteins. Furthermore, in other studies, staining by the antibody neither correlated with EpoR expression [19] nor could it differentiate between EpoR-positive and EpoR-negative cells in IHC (Fig. 2) [16-18]. One of the cross-reactive proteins that C-20 binds is heat-shock protein 70 (HSP-70), which was misidentified as EpoR in Western blotting experiments [16]. HSP-70 levels increase with stress-response [20]. Control experiments, using negative-control antibodies of the same isotype or antigen blocking, may eliminate some, but not all, types of false-positive results $[14,15]$.

Cell lines or tissues expressing/not-expressing EpoR should be used as positive and negative controls, respectively. However, few EpoR-positive cell types are available [21]. EpoR-positive cells also need to express physiologically relevant levels of EpoR protein to be informative. Purified-erythroid precursor cells that express EpoR and are Epo-responsive are difficult to obtain in large quantities. Tissues such as placenta [22] or cell lines such as HeLa [23], MCF-7 [24], or K562 [25], which have been used as EpoR-positive controls, are not Epo-responsive and express EpoR levels greatly below ( $>100$-fold lower) those of known Epo-responsive cells (e.g., erythroid progenitor or UT-7/Epo human-leukemic cells) [21], thereby raising questions about the validity of studies using them. When a specific and sensitive EpoR antibody is applied, EpoR is low to undetectable on immunostaining in non- 
Table 1 Common laboratory techniques for examining the cell biology of a protein receptor

\begin{tabular}{|c|c|c|}
\hline Detection method & Strengths & Limitations \\
\hline \multicolumn{3}{|l|}{ Genomic amplification } \\
\hline \multirow[t]{2}{*}{ FISH } & Localizes defect to cell & Semi-quantitative \\
\hline & Localizes defect to chromosome & May not correlate with gene expression \\
\hline \multirow[t]{2}{*}{ Array CGH } & Quantitative & May not correlate with gene expression or protein synthesis \\
\hline & Localizes defect to specific region of chromosome & Population based ${ }^{\mathrm{a}}$ \\
\hline \multirow[t]{3}{*}{ Southern blotting } & Easy to perform & Semi-quantitative \\
\hline & Moderately sensitive & Population based \\
\hline & & May not correlate with gene expression or protein synthesis \\
\hline \multicolumn{3}{|l|}{ mRNA analyses } \\
\hline \multirow[t]{4}{*}{ Northern blotting } & Determines transcript size & Insensitive \\
\hline & Determines potential spliced variants & Time consuming \\
\hline & & Population based \\
\hline & & May not correlate with protein synthesis \\
\hline \multirow[t]{3}{*}{ RT-PCR } & Easy to perform & Population based \\
\hline & Moderately sensitive & May not detect different spliced forms \\
\hline & Semi-quantitative & May not correlate with protein synthesis \\
\hline \multirow[t]{3}{*}{ Q-RT-PCR (Real Time) } & Moderately difficult to perform & Population based (unless laser-dissected samples) \\
\hline & Very sensitive & May not detect different spliced forms \\
\hline & Quantitative & May not correlate with protein synthesis \\
\hline \multirow[t]{4}{*}{ Microarray } & Easy to perform & Population based \\
\hline & Moderately sensitive & May not detect different spliced forms \\
\hline & Quantitative & May not correlate with protein synthesis \\
\hline & Broad gene profiling & \\
\hline \multicolumn{3}{|l|}{ Protein analyses } \\
\hline \multirow[t]{4}{*}{ ELISA } & Easy to perform & Need well-validated antibodies \\
\hline & Moderately sensitive & Population based \\
\hline & Quantitative & May not detect different spliced protein forms \\
\hline & & May not correlate with function \\
\hline \multirow[t]{4}{*}{ Western blotting } & Easy to perform & Need well-validated antibodies \\
\hline & Moderately sensitive & Population based \\
\hline & Semi quantitative & May not correlate with protein function \\
\hline & Protein sizes confirmed & Unable to determine location of expression in a cell \\
\hline \multirow[t]{4}{*}{$\mathrm{IHC}$} & Moderately difficult to perform & Need well-validated antibodies \\
\hline & Moderately sensitive & May not correlate with protein function \\
\hline & Semi-quantitative & May not detect different spliced protein forms \\
\hline & Determine location of protein expression in cell & \\
\hline \multirow[t]{3}{*}{ Binding assays } & Moderately sensitive & Need well-validated reagents \\
\hline & Easy to perform & May not correlate with protein function \\
\hline & Quantitative & May be able to detect different spliced forms \\
\hline
\end{tabular}

FISH fluorescence in situ hybridization, $C G H$ comparative genomic hybridization, $R T-P C R$ reverse transcriptase-polymerase chain reaction, $Q$ quantitative, ELISA enzyme-linked immunosorbent assay, IHC immunohistochemistry

${ }^{\text {a }}$ Population based refers to an analysis of multiple cells instead of a single cell

myeloid cells or tumor cells $[14,26]$ which is consistent with the low levels of EpoR transcripts in those cell types $[6,21]$.

In summary, IHC is widely used to identify clinically relevant receptors (EGFR, HER2), but proper controls should be employed with all IHC testing to detect both falsepositive and false-negative results. Use of IHC to identify EpoR has been hampered by lack of specific EpoR antibodies and of control cell types that clearly express/ do not express EpoR. 

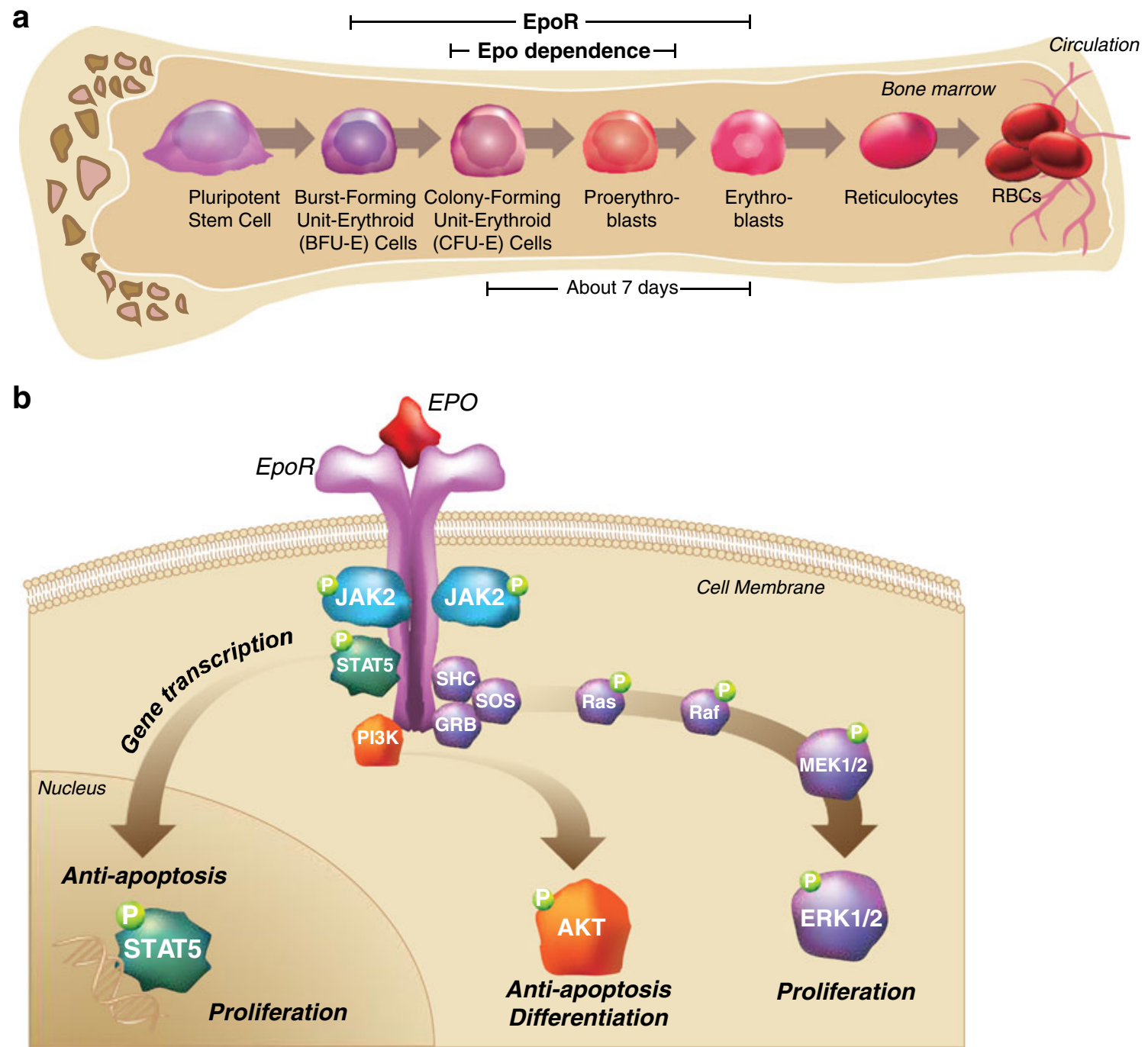

Fig. 1 The process of erythropoiesis. Erythroid progenitors in the bone marrow that depend on Epo and EpoR for differentiation into mature red blood cells (a). The signaling pathways stimulated by EpoR upon binding to Epo (b). EpoR erythropoietin receptor, Epo erythropoietin, $R B C s$ red blood cells. Adapted from Biologics: Targets and Therapy, Volume 6, Elliott S and Sinclair AM, The effect of erythropoietin on normal and neoplastic cells, pages 163-89, Copyright (2012), with permission from Dove Medical Press Ltd [6]

\section{Biology of Epo and EpoR}

\section{Physiological role of EpoR}

The inherent problems with many detection methodologies are highlighted by EpoR where confusion exists about its role in tumors. The principal function of the Epo/EpoR system is regulation of erythropoiesis. Epo stimulates erythropoiesis by binding and activating EpoR on the surface of erythrocytic progenitors in the bone marrow (Fig. 1a) [6]. Endogenous Epo is produced primarily in the kidneys and is regulated by oxygen tension. In blood plasma, Epo levels are approximately 10-20 mU/mL (5 pM), but can increase 1,000-fold with extreme hypoxia [6]. Interestingly, neither Epo nor EpoR are required for commitment to the erythroid lineage or for proliferation and differentiation of burst-forming units-erythroid (BFU-Es) to colony-forming unitserythroid (CFU-Es) [27, 28]. However, Epo and EpoR are crucial in vivo for the survival, proliferation, and terminal differentiation of the CFU-Es and their progeny.

Adult human Epo-responsive erythroblasts, which have the highest levels of EpoR, still have relatively low receptor protein levels compared to other receptor types (approximately 100-1,000 cell-surface EpoR molecules per cell). However, EpoR possess a very high affinity for Epo (dissociation constant [Kd] 100 pM) [29]. The EpoR density declines as cells differentiate into proerythroblasts. At the normoblast stage, cells stop dividing, extrude nuclei and mitochondria, and become reticulocytes that enter circulation. Reticulocytes and mature red blood cells do not express EpoR and are unresponsive to ESAs [29]. 

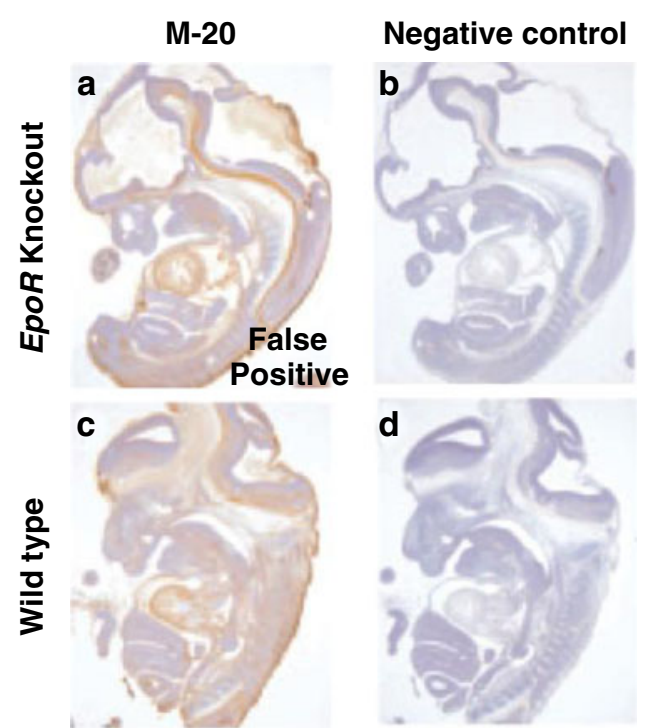

Fig. 2 Examples of false-positive IHC using commercial non-specific EpoR antibodies. Wild-type and $E p o R$ knockout-mouse embryos stained with non-specific "anti-EpoR" M-20 antibody (a, c) and rabbit-IgG antibody (negative control) (b, d). IHC in cell lines positive (UT-7/Epo)

EpoR transcription and translation

EpoR expression in erythropoietic tissues is not influenced by Epo [28, 30]. Rather, EpoR-gene transcription is controlled by erythroid-specific transcription factors, including GATA-1 [31] and stem-cell leukemia (SCL) protein [32], and EpoR transcript levels correlate with GATA1 and SCL transcript levels [6]. Thus, cell types lacking GATA-1 and SCL (e.g., those in non-hematopoietic tissues) express lower levels of EpoR transcripts [13]. EpoR mRNA is translated into a 508 amino-acid protein, which is translocated to the plasma membrane and transported to the cell surface [33, 34]. During this process, a signal peptide is removed and a carbohydrate chain added, resulting in a transmembrane protein with a calculated molecular mass of 56 to $57 \mathrm{kDa}$ [16]. To be Epo-responsive, cells must express EpoR on the cell surface [16]. In cells that express EpoR, however, $<10 \%$ of EpoR protein appears on the cell surface; the remainder is degraded into intracellular EpoR fragments that can be detected with specific EpoR antibodies [12, 21, 35, 36].

EpoR activation and downstream signaling

EpoR protein does not possess intrinsic tyrosine-kinase activity and requires accessory factors (e.g., Janus kinase 2 [JAK2]) for cell-surface transport and downstream signaling $[37,38]$. EpoR is activated when a single Epo molecule binds two cell-surface EpoR molecules and effectively "cross-links" them (Fig. 1b) [39-42]. Epo binding induces crossphosphorylation of EpoR and JAK2 [6, 43]. This activates downstream proteins such as signal transducer and activator of

\section{C-20}
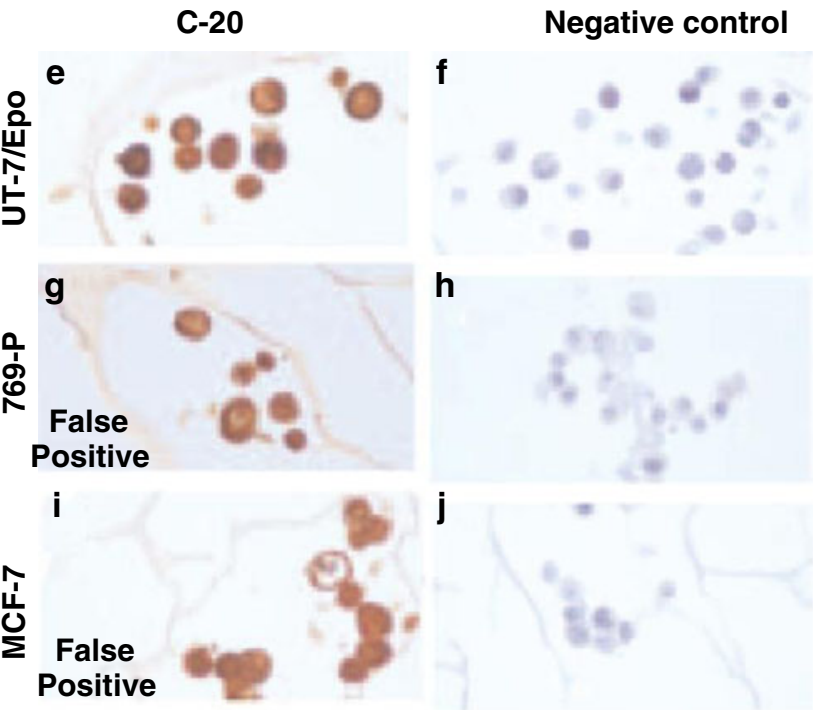

h

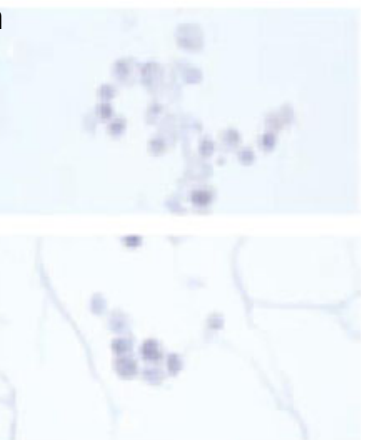

and negative (769-P, MCF-7) for EpoR using non-specific "anti-EpoR" C-20 antibody (e, $\mathbf{g}, \mathbf{i})$ and rabbit-IgG antibody (negative control) $(\mathbf{f}, \mathbf{h}, \mathbf{j})$. Adapted with permission: Blood 2006;107:1892-1895 [16]

transcription 5 (STAT5), extracellular-signal regulated kinase (ERK), and phosphatidylinositol-3 (PI3) kinase/AKT pathways [44]. Following activation, negative regulators of EpoR down-modulate responses [45, 46].

\section{Preclinical EpoR studies: from mRNA expression to functional testing}

mRNA expression: PCR, Northern blotting, and microarray

Presence of EpoR mRNA is necessary, but not sufficient, for the expression and functionality of EpoR protein. EpoR mRNA must be translated into protein that is translocated to the cell surface. These processes involve multiple and limiting molecular factors. Published techniques for detecting EpoR mRNA in solid-tumor cells include RT-PCR (including real time quantitative RT-PCR), microarray, and Northern blotting $[13,47,48]$. As with IHC, positive and negative controls are required. The mRNA levels must be evaluated, as sufficient levels are needed for EpoR protein synthesis, surface expression, and function (recall that low levels of EpoR may not be physiologically relevant and further that $<10 \%$ of EpoR protein is expressed on the cell surface). RT-PCR is sensitive and can detect low (basal) levels of mRNA transcripts, but at the cost of potentially nonspecific amplification and with questions about the significance of the detection. Northern blotting is less sensitive, but since it uses electrophoreses to separate mRNA samples by size, this parameter can be used to eliminate some false positive data. Microarrays allow for a broad examination of gene expression, but require careful 
analysis of multiple samples to provide definitive and quantitative results.

The above specified techniques have enabled detection of EpoR mRNA in some tumor and normal cells outside the erythroid compartment, but at relatively low quantities (at 101,000 -fold lower levels than in positive controls) $[6,13,19$, 26, 47, 49]. Unlike known oncogenes such as HER2 and $E G F R, E p o R$ mRNA is not elevated when tumor samples are compared with normal samples [47, 50, 51]. Reports suggesting otherwise were based on non-quantitative or uncontrolled RT-PCR studies [49].

In summary, methods of detecting EpoR mRNA are sensitive, but interpreting results requires controls to detect falsepositive data combined with quantitative methods to determine if mRNA levels are adequate to produce physiologically relevant amounts of functional EpoR protein.

\section{Western blotting}

Receptor protein can be detected by tests such as IHC (discussed earlier) and Western blotting. These tests require an antibody that specifically binds the receptor of interest. Western blotting involves separating proteins from a cell homogenate according to size, immobilizing them on a membrane, and using an antibody to detect a specific protein (Fig. 3). Since cell homogenates are used, intracellular and cell-surface proteins cannot be distinguished. Like IHC,
Western blotting can involve antibodies that cross-react with non-target proteins, particularly if non-target proteins contain a region with structural similarity to the target protein (Fig. 3). This problem occurs frequently with polyclonal antibodies but even monoclonal antibodies can show nonspecific cross reactivity to non-target proteins, especially when sensitive detection methods are used. Given that EpoR is expressed at low levels, cross-reactivity and false-positive results are particularly problematic with immunologic techniques. Confidence is increased in a positive result if the "band" detected corresponds to the correct size of the target protein. However, false-positive results can occur if a non-specific antibody recognizes a band of the correct size that is not the target protein as has occurred when using commercial antiEpoR polyclonal antibodies such as M20 from Santa Cruz, Inc. [14].

Western blot methodologies have been employed extensively in attempts to detect EpoR in extracts from tumors and tumor-cell lines. Positive results have been reported, but most came from studies that used antibodies with insufficient specificity/sensitivity to detect EpoR and that only rarely used appropriate control-cell types to exclude false-positive results $[16,49]$. Thus, incorrect proteins have been misclassified as EpoR $[14,16]$.

The full-length EpoR protein migrates at approximately $59 \mathrm{kDa}$ with polyacrylamide gel electrophoresis (Fig. 4) [16]. The commercially available, widely used Santa Cruz
Fig. 3 Specific and non-specific antibody binding to proteins on a Western blot. Cell homogenates are separated by size and proteins are detected with antibodies. A specific antibody will bind one particular protein (a). A nonspecific antibody will bind offtarget proteins (b). Antibody binding can be detected with a second antibody that emits a signal $(\mathbf{c}, \mathbf{d})$

\section{Specific Antibody Binding}

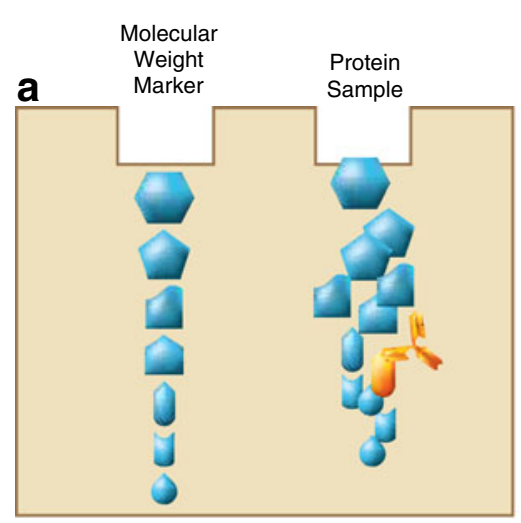

C

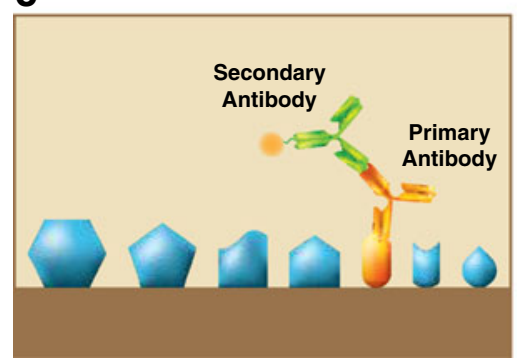

Non-specific Antibody Binding

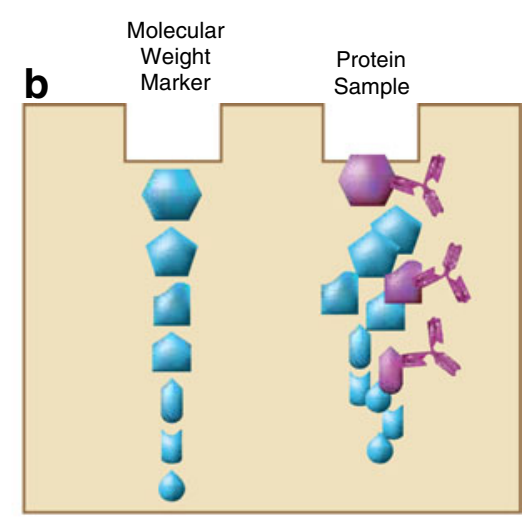

d

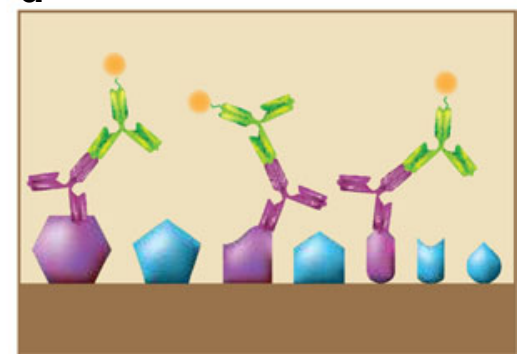




\section{a Non-specific antibody}

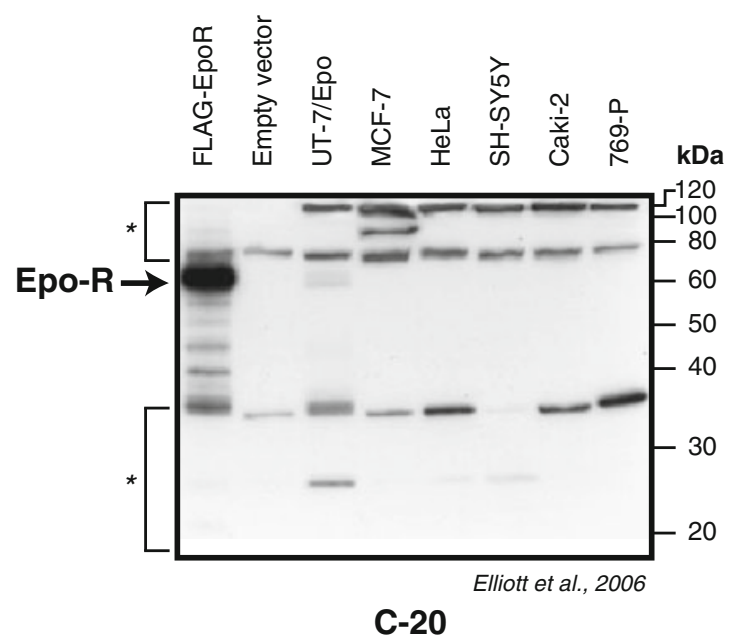

*Non-specific binding observed in negative controls (Empty vector and 769-P)

Fig. 4 Western blots showing non-specific and specific binding of EpoR antibodies to cellular proteins. The $59-\mathrm{kDa}$ EpoR protein is shown (arrow) in positive controls FLAG-EpoR and UT-7/Epo. Nonspecific C-20 antibody binds EpoR and other proteins (asterisk) (a). Specific-

polyclonal C-20 EpoR antibody was reported to detect a putative EpoR of $66 \mathrm{kDa}$ (Fig. 4) [16, 18]. However, this 66-kDa protein was identified as the cross-reacting HSP-70 that has some sequence homology to EpoR. When using a specific monoclonal anti-EpoR antibody suitable for Western blotting (such as monoclonal anti-EpoR antibody A82), a 59$\mathrm{kDa}$ EpoR protein can be detected in erythroid cell extracts but not in tumor biopsies [14] or most tumor-cell lines [21]. When EpoR protein was detected in cell lines, protein levels were 10- to 1,000-fold lower than those in cells known to bind or respond to Epo [13, 21].

\section{Binding assays}

The presence of cell-surface receptor protein on live cells can be determined by binding assays with labeled ligand or by flow cytometry with labeled antibodies to the receptor. However, non-specific binding is possible even with high-affinity ligands [52]. In addition, structural changes to the ligands can be introduced through the labeling process, which can increase off-target binding. As with IHC and Western blotting, the specificity and sensitivity of antibodies used for flow cytometry needs to be demonstrated.

Binding assays using labeled forms of Epo or anti-EpoR antibodies with flow cytometry have been used to detect cellsurface EpoR protein. ${ }^{125} \mathrm{I}$-rHuEpo or biotinylated-rHuEpo binding was detected on erythroid and some myeloid-cell types with a dissociation constant (Kd) of $\sim 100 \mathrm{pM}[29,53,54]$.

\section{b Specific antibody}

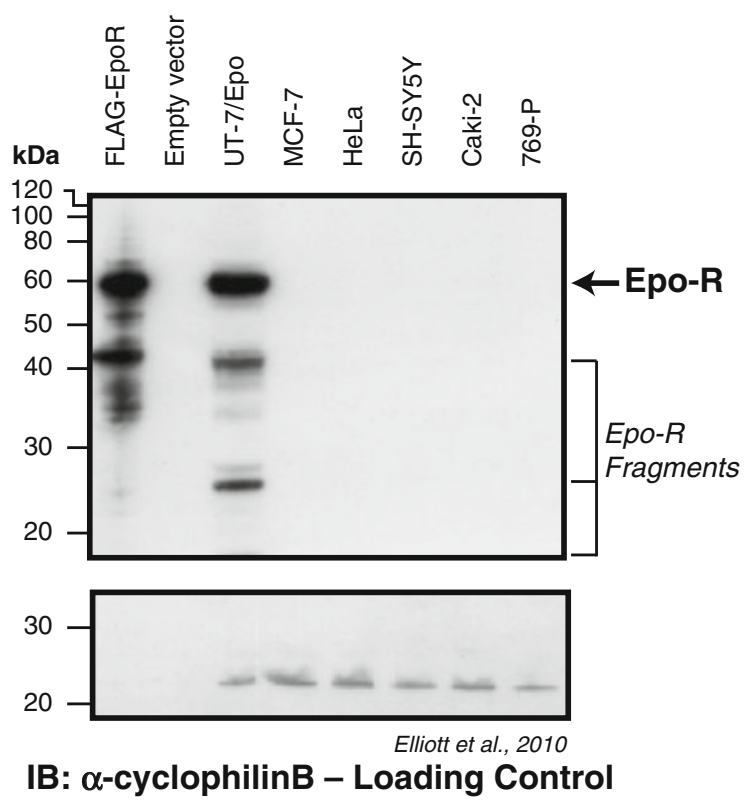

antibody A82 binds EpoR and EpoR fragments but not other proteins (b). Adapted with permission: Blood 2006;107:1892-1895 [16] and $J$. Immunol Methods 2010;352:126-139 [12]

However, in controlled experiments, no binding of either ${ }^{125} \mathrm{I}$ rHuEpo or of specific anti-EpoR antibodies to nonhematopoietic cells or primary-tumor cells was detected [21, 47]. In a survey of 61 non-hematopoietic tumor-cell lines, only one cell line had detectable (low level) EpoR protein on the cell surface [21]. Other binding studies suggested that EpoR could be detected on some non-hematopoietic tumor-cell lines [55]. In these studies, however, the Kd (10,000-16,000 pM) was 100-fold higher than that in EpoR positive-control cells, suggesting nonspecific binding.

Functional receptor testing

An alternative to direct measurements of receptors is to examine responses to ligand addition, thereby demonstrating that the receptor is not only present but functional. Such methods can be very sensitive but can also be prone to falsepositive results. Determining if a cell-surface receptor is functional requires demonstrating: (1) presence of intracellularsignaling networks responsive to binding of receptor ligand; (2) signaling occurs with relevant concentrations of receptor ligand; and (3) receptor concentrations are high enough to provide relevant signal strength. Similar to direct testing methods, appropriate controls must be used to detect falsepositive and false-negative results.

1. Appropriate intracellular-signaling networks must be present in cells for ligand responsiveness. 
Even if receptor mRNA or cell-surface proteins are detected, it is still necessary to demonstrate that intracellularsignaling networks are activated in response to the ligand binding the receptor. Demonstrating receptor activation can involve detecting phosphorylation of intracellular signalingpathway proteins known to operate downstream of the activated receptor in normal, responsive cells. Since ERK and AKT act downstream of EpoR in erythroid cells, activation of EpoR can be assessed by using antibodies that recognize phosphorylated epitopes of ERK and AKT. As noted above, such experiments require demonstration of antibody specificity and appropriate sensitivity. In some studies, ESA administration to tumor-cell lines increased phosphorylation of ERK [56, 57]. However, ERK and AKT act downstream of multiple ligand/receptor complexes [58] and can be phosphorylated in response to changes in culture medium, $\mathrm{pH}$, temperature [59], and bacterial lipopolysaccharide [60, 61], offering the possibility of false-positive results. Further, substances that can promote cell growth under certain conditions are found in Epo formulations, such as in serum or in bovine-serum albumin protein preparation used to stabilize rHuEpo. These substances can also induce signaling comparable to that observed in some ESA experiments with cell lines [59].

Demonstrating phosphorylation of the downstream signaling molecules JAK2 and STAT5 is more specific to EpoR activation than demonstrating ERK and AKT phosphorylation. However, investigators have not always evaluated phosphorylation of JAK2 and STAT5. For example, Gewirtz et al. [56] and Lester et al. [57] reported that rHuEpo stimulated ERK phosphorylation in MCF-7 breast-cancer cells, but did not evaluate effects on phosphorylation of STAT5 or JAK2. In addition, other investigators have been unable to duplicate those ERK results [18, 21], and control experiments suggest that the positive effects were likely due to contaminants or to medium changes, emphasizing the need for controls in such studies to rule out false-positive effects. Additionally, since EpoR requires accessory factors (e.g., JAK2) for transport to the cell surface and for signaling [38], examination of the phosphorylation status of JAK2 or STAT5 would be informative. However, such experiments are difficult to perform and negative results have been reported. Therefore, other indirect methods have been used. For example, inhibitors of JAK2 (e.g., AG490) were used to examine potential EpoR-mediated effects with positive results reported. An assumption of such experiments is that the inhibitors are specific to EpoR. Though AG490 inhibits multiple kinases, it has little/no inhibitory effect on JAK2 in vitro and, therefore, would not impact the EpoR signaling pathway [62]. Thus, data using such JAK2 inhibitors must be interpreted with caution.

2. Receptor signaling must occur in response to relevant ligand concentrations.
In several studies, there was increased proliferation of tumor-cell lines on Epo addition, but with supraphysiological Epo levels that were 10- to 1,000-fold greater than the maximum plasma level observed in patients receiving approved Epo doses. For example, one report described how culturing cells in a medium containing $250,000 \mathrm{mU} / \mathrm{mL}$ rHuEpo resulted in EpoR-mediated tyrosine phosphorylation [63]. With administration of such high Epo doses, false-positive results can occur due to non-specific vehicle effects or low-level growth-promoting contaminants.

3. Enough receptor must be present to provide a meaningful response.

Studies suggest that EpoR-protein levels are very low in tumors and tumor-cell lines. As one example, MCF-7 breastcancer cells have a total of only 100 EpoR dimers/cell vs the $\sim 10,000$ receptors (surface plus cytoplasmic EpoR) seen in erythroid progenitors [21] but have been reported to respond to Epo addition. Given the inefficient transport of EpoR to the cell surface, the number of EpoR molecules available for ligand binding on MCF-7 cells would be very low. Accordingly, there is conflicting data with MCF-7 cells as Laugsch et al. [18] and other groups [21] were unable to confirm reports that rHuEpo stimulated proliferation of MCF-7 and other cell lines where EpoR levels are very low. Another confounding factor is that non-hematopoietic cells and tumor cells may not have the same signaling networks found in erythroid-progenitor cells or may have constitutive activation of pathways. Either can render the cells nonresponsive to growth factor challenge. Thus, cells may not respond to Epo, even with high-level EpoR expression. Consistent with this, forced overexpression of EpoR in some factor-dependent myeloid cells or solid-tumor cell lines does not result in Epo responsiveness [64, 65].

Apart from cell culture work, another approach is to employ animal experiments. Studies using rodent-tumor models have indicated that ESA administration alone does not stimulate tumor proliferation [49]. In addition, ESAs could hypothetically inhibit the effects of concurrently administered anticancer therapy. One report indicated that rHuEpo alone had no effect on MCF-7 cell growth in animals, but that tumor size increased in trastuzumabtreated animals [66]. However, as noted above, MCF-7 cells express minimal levels of EpoR and in studies by other groups, treating MCF-7 cells with Epo failed to interfere with the antiproliferative and/or cytotoxic effects of either bevacizumab or paclitaxel $[67,68]$.

In summary, demonstrating functional EpoR requires proof that cell-surface EpoR molecules exist in adequate concentration and that downstream signaling occurs in response to relevant ligand concentrations. In addition, tests must be performed using positive and negative controls. 


\section{EpoR mutations/amplification and Epo overexpression}

Mutations in genomic-coding sequences of receptor genes can be tumorigenic or alter the potential for receptors to signal. These include mutations that constitutively activate a receptor, increase gene-copy number (and ultimately gene-expression level of a receptor), or alter factors that regulate protein processing, which can lead to receptor overproduction. These mutations are usually identified through specific DNA sequencing of the gene on genomic clones, through sequencing of mRNAs encoding the protein (using PCR/cloning), or through complete genome/transcriptome sequencing using next-generation sequencing methodologies.

\section{EpoR mutations}

A mutation in murine $E p o R, \mathrm{R} 129 \mathrm{C}$, was identified that results in EpoR dimerization and constitutive activation. In mice, this mutation causes erythroid and granulocyte/ monocyte colony-expansion but not expansion of other hematopoietic lineages, indicating that nonmyeloid-cell types have a limited response to activated EpoR [69-71].

To date, no EpoR mutations have been reported in any solid tumors. EpoR-activating mutations have not been observed in erythroleukemias [72, 73], and erythroleukemias are not associated with alterations to chromosome 19 where the EpoR gene is located [72]. EpoR-hyperactivity truncation mutations cause erythrocytosis in humans $[74,75]$, but not leukemias or tumors $[72,76]$. When Gonda et al. [72] screened ten human cases of erythroleukemia, no EpoR-gene mutations were found.

In summary, though EpoR hyperactivity can cause erythrocytosis and erythroleukemia in mice, no evidence to date suggests that EpoR hyperactivating mutations in humans increase cancer risk or enhance tumor growth.

\section{EpoR gene amplification}

Amplification of certain oncogenic receptors (e.g., HER2 or $E G F R$ ) is characteristic of some aggressive tumors. Amplification of the EpoR gene has been detected in some cell lines derived from AML, CML, and erythroleukemia patients (e.g., UT-7 and TF-1) consistent with their myeloid origin [77, 78]. This amplification may provide these cells with a growth advantage when treated with ESAs. However, EpoR-gene amplification is not a characteristic of solid tumors. A geneamplification analysis of 1,083 solid tumors showed that EpoR-gene amplification was rare; overall, the EpoR-gene frequency was similar to other non-oncogenes [47].

\section{Epo overexpression}

Another suggested theory is that long-term exposure to elevated levels of Epo might induce tumors. However, this theory is not supported by patients with mutations resulting in lifetime elevated-Epo levels. Increased cancer incidence is not observed in patients with Chuvash polycythemia who have increased levels of endogenous Epo [79, 80]. Similarly, people living at high altitude $(>3,000 \mathrm{ft})$ with chronically elevated endogenous Epo have no increase in tumor incidence, tumor mortality, or tumor recurrence compared with those living at sea level [81]. In summary, elevated levels of endogenous Epo do not appear to increase the incidence of cancer.

\section{Angiogenesis}

As an alternative to direct stimulation of tumors via resident receptors, tumor growth may be increased if an activated receptor stimulates angiogenesis. During angiogenesis, new vessels arise from existing vessels through endothelial branching, sprouting, migration, and proliferation [82, 83]. One hypothesis is that Epo or exogenous ESAs could stimulate tumor growth by activating EpoR on endothelial cells to facilitate angiogenesis near tumors.

While several groups have reported detection of EpoR on endothelial cells, those results are controversial because of the same antibody non-specificity issues reported above for IHC and Western blotting. When a specific EpoR antibody was used to evaluate EpoR on endothelial cells [13], little EpoR protein was detected. Further, rHuEpo does not appear to bind to endothelial cells, and ESAs exerted no effect on endothelial cells in controlled experiments performed in vitro or in vivo [13, 84-86]. Studies in EpoR-null mutant mice expressing EpoR exclusively in the hematopoietic lineage have shown that the Epo-EpoR signaling pathway is not necessary for endothelial cell development [11]. In tumor-xenograft studies, no effect on angiogenesis was observed with ESAs [87-89]. In contrast to these data, there are positive results suggesting ESAs can stimulate angiogenesis. For example, Yamaji et al. [90] reported increased proliferation (as measured by thymidine incorporation) of brain-capillary endothelial cells following Epo addition but only when accompanied by a change in medium. Though one group noted that angiogenesis increases in chicken eggs treated with rHuEpo [91-93], there is no cross-species activity of human Epo in chickens [94]. These questionable studies highlight the importance of appropriate controls to aid in interpretation of the data.

\section{Conclusion}

The presence of a specific cell-surface receptor can be detected using multiple methodologies with recommended standard procedures involving (1) receptor-specific antibodies, (2) binding of radiolabeled ligands (however, to be interpretable, the experiments must include both negative and positive 
controls and quantification of results to confirm that receptor levels correlate with known levels needed for function), and (3) confirmation of receptor size at the appropriate molecular mass (kilodaltons). Strategies and guidelines for these standard procedures have been published and should be followed $[12,15,26]$.

Given the complexity of the issues involved, growth-factor receptor research in cancers should be evaluated in light of the techniques and controls used. Limitations in these techniques can lead to contradictory results as shown here regarding research on whether functional EpoR is present on nonerythroid cells.

Acknowledgments The authors thank Heather Hartley-Thorne for assistance with creating the figures and thank Shawn Lee for providing editorial support on the manuscript on behalf of Amgen Inc. This study was supported by Amgen Inc., Thousand Oaks, CA.

Conflict of interest SE discloses a compensated employment/ leadership position with Amgen Inc., a consultant/advisory role with Amgen Inc., and ownership interest in Amgen Inc. AS, HC, and LR were compensated employees of Amgen Inc. during the preparation of this manuscript and own Amgen Inc. stock. WJ has had a compensated consultant/advisory role with Amgen Inc. and has received honoraria and research funding from Amgen Inc.

Open Access This article is distributed under the terms of the Creative Commons Attribution License which permits any use, distribution, and reproduction in any medium, provided the original author(s) and the source are credited.

\section{References}

1. Allegra CJ, Jessup JM, Somerfield MR, Hamilton SR, Hammond EH, Hayes DF, McAllister PK, Morton RF, Schilsky RL (2009) American Society of Clinical Oncology provisional clinical opinion: testing for KRAS gene mutations in patients with metastatic colorectal carcinoma to predict response to anti-epidermal growth factor receptor monoclonal antibody therapy. J Clin Oncol 27(12):20912096. doi:10.1200/JCO.2009.21.9170

2. Cobleigh MA, Vogel CL, Tripathy D, Robert NJ, Scholl S, Fehrenbacher L, Wolter JM, Paton V, Shak S, Lieberman G, Slamon DJ (1999) Multinational study of the efficacy and safety of humanized anti-HER2 monoclonal antibody in women who have HER2-overexpressing metastatic breast cancer that has progressed after chemotherapy for metastatic disease. J Clin Oncol 17(9):2639 2648

3. Paik S, Bryant J, Tan-Chiu E, Romond E, Hiller W, Park K, Brown A, Yothers G, Anderson S, Smith R, Wickerham DL, Wolmark N (2002) Real-world performance of HER2 testing - National Surgical Adjuvant Breast and Bowel Project experience. J Natl Cancer Inst 94(11):852-854

4. Perez EA, Suman VJ, Davidson NE, Martino S, Kaufman PA, Lingle WL, Flynn PJ, Ingle JN, Visscher D, Jenkins RB (2006) HER2 testing by local, central, and reference laboratories in specimens from the North Central Cancer Treatment Group N9831 intergroup adjuvant trial. J Clin Oncol 24(19):3032-3038. doi:10.1200/JCO.2005. 03.4744

5. Wolff AC, Hammond ME, Schwartz JN, Hagerty KL, Allred DC, Cote RJ, Dowsett M, Fitzgibbons PL, Hanna WM, Langer A,
McShane LM, Paik S, Pegram MD, Perez EA, Press MF, Rhodes A, Sturgeon C, Taube SE, Tubbs R, Vance GH, van de Vijver M, Wheeler TM, Hayes DF (2007) American Society of Clinical Oncology/College of American Pathologists guideline recommendations for human epidermal growth factor receptor 2 testing in breast cancer. Arch Pathol Lab Med 131(1):18-43. doi:10.1043/15432165(2007)131[18:ASOCCO]2.0.CO;2

6. Elliott S, Sinclair AM (2012) The effect of erythropoietin on normal and neoplastic cells. Biologics: Targets and Therapy 6:163-189

7. Amgen Inc. (2011) Aranesp ${ }^{\circledR}$ (Darbepoetin alfa) prescribing information. Amgen Inc., Thousand Oaks

8. Henke M, Mattern D, Pepe M, Bezay C, Weissenberger C, Werner M, Pajonk F (2006) Do erythropoietin receptors on cancer cells explain unexpected clinical findings? J Clin Oncol 24(29):47084713

9. Osterborg A, Aapro M, Cornes P, Haselbeck A, Hayward CR, Jelkmann W (2007) Preclinical studies of erythropoietin receptor expression in tumour cells: impact on clinical use of erythropoietic proteins to correct cancer-related anaemia. Eur J Cancer 43(3):510 519

10. Ribatti D (2010) Erythropoietin and tumor angiogenesis. Stem Cells Dev 19(1):1-4

11. Suzuki N, Ohneda O, Takahashi S, Higuchi M, Mukai HY, Nakahata T, Imagawa S, Yamamoto M (2002) Erythroid-specific expression of the erythropoietin receptor rescued its null mutant mice from lethality. Blood 100(7):2279-2288

12. Elliott S, Busse L, McCaffery I, Rossi J, Sinclair A, Spahr C, Swift S, Begley CG (2010) Identification of a sensitive anti-erythropoietin receptor monoclonal antibody allows detection of low levels of EpoR in cells. J Immunol Methods 352(1-2):126-139

13. Sinclair AM, Coxon A, McCaffery I, Kaufman S, Paweletz K, Liu L, Busse L, Swift S, Elliott S, Begley CG (2010) Functional erythropoietin receptor is undetectable in endothelial, cardiac, neuronal, and renal cells. Blood 115:4264-4272

14. Elliott S, Swift S, Busse L, Scully S, Van G, Rossi J, Johnson C (2013) Epo receptors are not detectable in primary human tumor tissue samples. PLoS One 8(7):e68083

15. Bordeaux J, Welsh A, Agarwal S, Killiam E, Baquero M, Hanna J, Anagnostou V, Rimm D (2010) Antibody validation. Biotechniques 48(3):197-209

16. Elliott S, Busse L, Bass MB, Lu H, Sarosi I, Sinclair AM, Spahr C, Um M, Van G, Begley CG (2006) Anti-Epo receptor antibodies do not predict Epo receptor expression. Blood 107(5):18921895

17. Kirkeby A, van Beek J, Nielsen J, Leist M, Helboe L (2007) Functional and immunochemical characterisation of different antibodies against the erythropoietin receptor. J Neurosci Methods 164(1):50-58

18. Laugsch M, Metzen E, Svensson T, Depping R, Jelkmann W (2008) Lack of functional erythropoietin receptors of cancer cell lines. Int $\mathrm{J}$ Cancer 122(5):1005-1011

19. Miller CP, Lowe KA, Valliant-Saunders K, Kaiser JF, Mattern D, Urban N, Henke M, Blau CA (2009) Evaluating erythropoietinassociated tumor progression using archival tissues from a phase III clinical trial. Stem Cells 27(9):2353-2361

20. Weinstein PR, Hong S, Sharp FR (2004) Molecular identification of the ischemic penumbra. Stroke 35(11 Suppl 1):2666-2670. doi:10. 1161/01.STR.0000144052.10644.ed

21. Swift S, Ellison AR, Kassner P, McCaffery I, Rossi J, Sinclair AM, Begley CG, Elliott S (2010) Absence of functional EpoR expression in human tumor cell lines. Blood 115:4254-4263

22. Saintigny P, Besse B, Callard P, Vergnaud AC, Czernichow S, Colombat M, Girard P, Validire P, Breau JL, Bernaudin JF, Soria JC (2007) Erythropoietin and erythropoietin receptor coexpression is associated with poor survival in stage I non-small cell lung cancer. Clin Cancer Res 13(16):4825-4831 
23. Lopez TV, Lappin TR, Maxwell P, Shi Z, Lopez-Marure R, Aguilar C, Rocha-Zavaleta L (2011) Autocrine/paracrine erythropoietin signalling promotes JAK/STAT-dependent proliferation of human cervical cancer cells. Int J Cancer 129(11):2566-2576. doi:10.1002/ijc.25935

24. Palumbo C, Battisti S, Carbone D, Albonici L, Alimandi M, Bei R, Modesti A (2008) Recombinant erythropoietin differently affects proliferation of mesothelioma cells but not sensitivity to cisplatin and pemetrexed. Cancer Chemother Pharmacol 61(5):893-901

25. Yin D, Kawabata H, Tcherniamtchouk O, Huynh T, Black KL, Koeffler HP (2007) Glioblastoma multiforme cells: expression of erythropoietin receptor and response to erythropoietin. Int J Oncol 31(5):1193-1198

26. Elliott S, Busse L, Swift S, McCaffery I, Rossi J, Kassner P, Begley CG (2012) Lack of expression and function of erythropoietin receptors in the kidney. Nephrol Dial Transplant 27:2733-2745

27. Lin CS, Lim SK, D’Agati V, Costantini F (1996) Differential effects of an erythropoietin receptor gene disruption on primitive and definitive erythropoiesis. Genes Dev 10(2):154-164

28. Wu H, Liu X, Jaenisch R, Lodish HF (1995) Generation of committed erythroid BFU-E and CFU-E progenitors does not require erythropoietin or the erythropoietin receptor. Cell 83(1):59-67

29. Broudy VC, Lin N, Brice M, Nakamoto B, Papayannopoulou T (1991) Erythropoietin receptor characteristics on primary human erythroid cells. Blood 77(12):2583-2590

30. Zeigler BM, Vajdos J, Qin W, Loverro L, Niss K (2010) A mouse model for an erythropoietin-deficiency anemia. Dis Model Mech 3(11-12):763-772. doi:10.1242/dmm.004788

31. Zon LI, Youssoufian H, Mather C, Lodish HF, Orkin SH (1991) Activation of the erythropoietin receptor promoter by transcription factor GATA-1. Proc Natl Acad Sci U S A 88(23):10638-10641

32. Kassouf MT, Hughes JR, Taylor S, McGowan SJ, Soneji S, Green AL, Vyas P, Porcher C (2010) Genome-wide identification of TAL1's functional targets: insights into its mechanisms of action in primary erythroid cells. Genome Res 20(8):1064-1083

33. D'Andrea AD, Fasman GD, Lodish HF (1989) Erythropoietin receptor and interleukin-2 receptor beta chain: a new receptor family. Cell 58(6):1023-1024

34. Jones SS, D'Andrea AD, Haines LL, Wong GG (1990) Human erythropoietin receptor: cloning, expression, and biologic characterization. Blood 76(1):31-35

35. Hilton DJ, Watowich SS, Murray PJ, Lodish HF (1995) Increased cell surface expression and enhanced folding in the endoplasmic reticulum of a mutant erythropoietin receptor. Proc Natl Acad Sci U S A 92(1):190-194

36. Neumann D, Wikstrom L, Watowich SS, Lodish HF (1993) Intermediates in degradation of the erythropoietin receptor accumulate and are degraded in lysosomes. J Biol Chem 268(18):1363913649

37. Constantinescu SN, Ghaffari S, Lodish HF (1999) The erythropoietin receptor: structure, activation and intracellular signal transduction. Trends Endocrinol Metab 10(1):18-23

38. Huang LJ, Constantinescu SN, Lodish HF (2001) The N-terminal domain of Janus kinase 2 is required for Golgi processing and cell surface expression of erythropoietin receptor. Mol Cell 8(6):13271338

39. Narhi LO, Aoki KH, Philo JS, Arakawa T (1997) Changes in conformation and stability upon formation of complexes of erythropoietin (EPO) and soluble EPO receptor. J Protein Chem 16(3): 213-225

40. Philo JS, Aoki KH, Arakawa T, Narhi LO, Wen J (1996) Dimerization of the extracellular domain of the erythropoietin (EPO) receptor by EPO: one high-affinity and one low-affinity interaction. Biochemistry 35(5):1681-1691

41. Syed RS, Reid SW, Li C, Cheetham JC, Aoki KH, Liu B, Zhan H, Osslund TD, Chirino AJ, Zhang J, Finer-Moore J, Elliott S, Sitney K, Katz BA, Matthews DJ, Wendoloski JJ, Egrie J, Stroud RM (1998)
Efficiency of signalling through cytokine receptors depends critically on receptor orientation. Nature 395(6701):511-516

42. Watowich SS (1999) Activation of erythropoietin signaling by receptor dimerization. Int J Biochem Cell Biol 31(10):1075-1088

43. Remy I, Wilson IA, Michnick SW (1999) Erythropoietin receptor activation by a ligand-induced conformation change. Science 283(5404):990-993

44. Jelkmann W, Bohlius J, Hallek M, Sytkowski AJ (2008) The erythropoietin receptor in normal and cancer tissues. Crit Rev Oncol Hematol 67(1):39-61. doi:10.1016/j.critrevonc.2008.03.006

45. Jegalian AG, Wu H (2002) Differential roles of SOCS family members in EpoR signal transduction. J Interferon Cytokine Res 22(8): $853-860$

46. Minoo P, Zadeh MM, Rottapel R, Lebrun JJ, Ali S (2004) A novel SHP-1/Grb2-dependent mechanism of negative regulation of cytokine-receptor signaling: contribution of SHP-1 C-terminal tyrosines in cytokine signaling. Blood 103(4):1398-1407

47. Sinclair AM, Rogers N, Busse L, Archibeque I, Brown W, Kassner PD, Watson JEV, Arnold GE, Nguyen KCQ, Powers S, Elliott S (2008) Erythropoietin receptor transcription is neither elevated nor predictive of surface expression in human tumour cells. Br J Cancer 98(6):1059-1067

48. Su AI, Wiltshire T, Batalov S, Lapp H, Ching KA, Block D, Zhang J, Soden R, Hayakawa M, Kreiman G, Cooke MP, Walker JR, Hogenesch JB (2004) A gene atlas of the mouse and human protein-encoding transcriptomes. Proc Natl Acad Sci U S A 101(16):6062-6067

49. Sinclair AM, Todd MD, Forsythe K, Knox SJ, Elliott S, Begley CG (2007) Expression and function of erythropoietin receptors in tumors: implications for the use of erythropoiesis-stimulating agents in cancer patients. Cancer 110(3):477-488

50. Volgger B, Kurz K, Zoschg K, Theurl I, Ciresa-Konig A, Marth C, Weiss G (2010) Importance of erythropoetin receptor expression in tumour tissue for the clinical course of breast cancer. Anticancer Res 30(9):3721-3726

51. Winter SC, Shah KA, Campo L, Turley H, Leek R, Corbridge RJ, Cox GJ, Harris AL (2005) Relation of erythropoietin and erythropoietin receptor expression to hypoxia and anemia in head and neck squamous cell carcinoma. Clin Cancer Res 11(21):7614-7620

52. vanZoelen EJ (1989) Receptor-ligand interaction: a new method for determining binding parameters without a priori assumptions on nonspecific binding. Biochem J 262(2):549-556

53. Komatsu N, Yamamoto M, Fujita H, Miwa A, Hatake K, Endo T, Okano H, Katsube T, Fukumaki Y, Sassa S et al (1993) Establishment and characterization of an erythropoietin-dependent subline, UT-7/ Epo, derived from human leukemia cell line, UT-7. Blood 82(2):456464

54. Sawada K, Krantz SB, Sawyer ST, Civin CI (1988) Quantitation of specific binding of erythropoietin to human erythroid colony-forming cells. J Cell Physiol 137(2):337-345

55. Ohigashi T, Yoshioka K, Fisher JW (1996) Autocrine regulation of erythropoietin gene expression in human hepatocellular carcinoma cells. Life Sci 58(5):421-427

56. Gewirtz DA, Di X, Walker TD, Sawyer ST (2006) Erythropoietin fails to interfere with the antiproliferative and cytotoxic effects of antitumor drugs. Clin Cancer Res 12(7:Pt 1):2232-2238

57. Lester RD, Jo M, Campana WM, Gonias SL (2005) Erythropoietin promotes MCF-7 breast cancer cell migration by an ERK/mitogenactivated protein kinase-dependent pathway and is primarily responsible for the increase in migration observed in hypoxia. J Biol Chem 280(47):39273-39277

58. Datta SR, Brunet A, Greenberg ME (1999) Cellular survival: a play in three Akts. Genes Dev 13(22):2905-2927

59. Swift S, Elliott S, Sinclair A, Begley CG (2010) Erythropoietin receptor in ovarian cancer cells-letter. Mol Cancer Ther 9(4): 1070-1071 
60. Doan HQ, Bowen KA, Jackson LA, Evers BM (2009) Toll-like receptor 4 activation increases Akt phosphorylation in colon cancer cells. Anticancer Res 29(7):2473-2478

61. Hsu RY, Chan CH, Spicer JD, Rousseau MC, Giannias B, Rousseau S, Ferri LE (2011) LPS-induced TLR4 signaling in human colorectal cancer cells increases beta1 integrin-mediated cell adhesion and liver metastasis. Cancer Res 71(5):1989-1998

62. Sinclair A, Archibeque I, Zhan J, Liu L, Emkey R, Doherty E, Begley CG (2011) Potency and selectivity assessment of small molecules against Janus Kinase (JAK) 2: Widely used AG490 inhibitor is neither potent, nor selective for JAK2. Blood 118:Abstract 4780

63. Acs G, Acs P, Beckwith SM, Pitts RL, Clements E, Wong K, Verma A (2001) Erythropoietin and erythropoietin receptor expression in human cancer. Cancer Res 61(9):3561-3565

64. Kang JK, Chang CH, Nam HJ, Kim SK, Ahn KJ, Seok H, Park SJ, Kang YJ, Jo YS, Shong M, Kim H (2011) Downregulation of erythropoietin receptor by overexpression of phospholipase Cgamma 1 is critical for decrease on focal adhesion in transformed cells. Cell Oncol (Dordr) 34(1):11-21

65. Layon ME, Ackley CJ, West RJ, Lowrey CH (2007) Expression of GATA-1 in a non-hematopoietic cell line induces beta-globin locus control region chromatin structure remodeling and an erythroid pattern of gene expression. J Mol Biol 366(3):737-744

66. Liang K, Esteva FJ, Albarracin C, Stemke-Hale K, Lu Y, Bianchini G, Yang CY, Li Y, Li X, Chen CT, Mills GB, Hortobagyi GN, Mendelsohn J, Hung MC, Fan Z (2010) Recombinant human erythropoietin antagonizes trastuzumab treatment of breast cancer cells via Jak2-mediated Src activation and PTEN inactivation. Cancer Cell 18(5):423-435

67. Kataoka M, Moriya Y, Moriguchi Y, Iwai T, Fujimoto-Ouchi K, Shirane M, Kondoh K, Mori K (2010) Effect of erythropoietin on human tumor growth in xenograft models. Mol Med Report 3(1):95-101

68. LaMontagne KR, Butler J, Marshall DJ, Tullai J, Gechtman Z, Hall C, Meshaw A, Farrell FX (2006) Recombinant epoetins do not stimulate tumor growth in erythropoietin receptor-positive breast carcinoma models. Mol Cancer Ther 5(2):347-355

69. Longmore GD, Pharr PN, Lodish HF (1994) A constitutively activated erythropoietin receptor stimulates proliferation and contributes to transformation of multipotent, committed nonerythroid and erythroid progenitor cells. Mol Cell Biol 14(4):2266-2277

70. McArthur GA, Longmore GD, Klingler K, Johnson GR (1995) Lineage-restricted recruitment of immature hematopoietic progenitor cells in response to Epo after normal hematopoietic cell transfection with EpoR. Exp Hematol 23(7):645-654

71. Pharr PN, Ogawa M, Hofbauer A, Longmore GD (1994) Expression of an activated erythropoietin or a colony-stimulating factor 1 receptor by pluripotent progenitors enhances colony formation but does not induce differentiation. Proc Natl Acad Sci U S A 91(16):7482-7486

72. Gonda TJ, D'Andrea RJ (1997) Activating mutations in cytokine receptors: implications for receptor function and role in disease. Blood 89(2):355-369

73. Le Couedic JP, Mitjavila MT, Villeval JL, Feger F, Gobert S, Mayeux P, Casadevall N, Vainchenker W (1996) Missense mutation of the erythropoietin receptor is a rare event in human erythroid malignancies. Blood 87(4):1502-1511

74. Al-Sheikh M, Mazurier E, Gardie B, Casadevall N, Galacteros F, Goossens M, Wajcman H, Prehu C, Ugo V (2008) A study of 36 unrelated cases with pure erythrocytosis revealed three new mutations in the erythropoietin receptor gene. Haematologica 93(7):1072-1075

75. Rives S, Pahl HL, Florensa L, Bellosillo B, Neusuess A, Estella J, Debatin KM, Kohne E, Schwarz K, Cario H (2007) Molecular genetic analyses in familial and sporadic congenital primary erythrocytosis. Haematologica 92(5):674-677

76. Gordeuk VR, Sergueeva AI, Miasnikova GY, Okhotin D, Voloshin Y, Choyke PL, Butman JA, Jedlickova K, Prchal JT, Polyakova LA (2004) Congenital disorder of oxygen sensing: association of the homozygous Chuvash polycythemia VHL mutation with thrombosis and vascular abnormalities but not tumors. Blood 103(10):3924-3932

77. Chretien S, Moreau-Gachelin F, Apiou F, Courtois G, Mayeux P, Dutrillaux B, Cartron JP, Gisselbrecht S, Lacombe C (1994) Putative oncogenic role of the erythropoietin receptor in murine and human erythroleukemia cells. Blood 83(7):1813-1821

78. Winkelmann JC, Ward J, Mayeux P, Lacombe C, Schimmenti L, Jenkins RB (1995) A translocated erythropoietin receptor gene in a human erythroleukemia cell line (TF-1) expresses an abnormal transcript and a truncated protein. Blood 85(1):179-185

79. Sergeyeva A, Gordeuk VR, Tokarev YN, Sokol L, Prchal JF, Prchal JT (1997) Congenital polycythemia in Chuvashia. Blood 89(6):2148-2154

80. Ang SO, Chen H, Hirota K, Gordeuk VR, Jelinek J, Guan Y, Liu E, Sergueeva AI, Miasnikova GY, Mole D, Maxwell PH, Stockton DW, Semenza GL, Prchal JT (2002) Disruption of oxygen homeostasis underlies congenital Chuvash polycythemia. Nat Genet 32(4):614-621

81. Amsel J, Waterbor JW, Oler J, Rosenwaike I, Marshall K (1982) Relationship of site-specific cancer mortality rates to altitude. Carcinogenesis 3(5):461-465

82. Herbert SP, Stainier DY (2011) Molecular control of endothelial cell behaviour during blood vessel morphogenesis. Nat Rev Mol Cell Biol 12(9):551-564. doi:10.1038/nrm3176

83. Geudens I, Gerhardt H (2011) Coordinating cell behaviour during blood vessel formation. Development 138(21):4569-4583. doi:10. $1242 /$ dev. 062323

84. Ammarguellat F, Gogusev J, Drueke TB (1996) Direct effect of erythropoietin on rat vascular smooth-muscle cell via a putative erythropoietin receptor. Nephrol Dial Transplant 11(4):687-692

85. Fuste B, Diaz-Ricart M, Cases A, Lopez-Pedret J, Ordinas A, Escolar G (2002) Erythropoietin does not modify the prothrombotic effect induced by uremic media on endothelial cells. Haematologica 87(9): 1006-1008

86. Lopez Ongil SL, Saura M, Lamas S, Rodriguez PM, Rodriguez PD (1996) Recombinant human erythropoietin does not regulate the expression of endothelin-1 and constitutive nitric oxide synthase in vascular endothelial cells. Exp Nephrol 4(1):37-42

87. Hardee ME, Kirkpatrick JP, Shan S, Snyder SA, Vujaskovic Z, Rabbani ZN, Dewhirst MW, Blackwell KL (2005) Human recombinant erythropoietin (rEpo) has no effect on tumour growth or angiogenesis. Br J Cancer 93(12):1350-1355

88. Pinel S, Barberi-Heyob M, Cohen-Jonathan E, Merlin JL, Delmas C, Plenat F, Chastagner P (2004) Erythropoietin-induced reduction of hypoxia before and during fractionated irradiation contributes to improvement of radioresponse in human glioma xenografts. Int $\mathrm{J}$ Radiat Oncol Biol Phys 59(1):250-259

89. Sairah AK, Rasedee A, Sheikh O, Rozita R, Alhaj N (2009) The effects of recombinant human erythropoietin and tamoxifen on growth and angiogenesis of mammary tumor in Sprague-Dawley rat. Am J Pharmacol Toxicol 4(1):12-16

90. Yamaji R, Okada T, Moriya M, Naito M, Tsuruo T, Miyatake K, Nakano Y (1996) Brain capillary endothelial cells express two forms of erythropoietin receptor mRNA. Eur J Biochem 239(2):494-500

91. Crivellato E, Nico B, Vacca A, Djonov V, Presta M, Ribatti D (2004) Recombinant human erythropoietin induces intussusceptive microvascular growth in vivo. Leukemia 18(2):331-336

92. Nico B, Annese T, Guidolin D, Finato N, Crivellato E, Ribatti D (2011) Epo is involved in angiogenesis in human glioma. J Neurooncol 102(1):51-58

93. Ribatti D, Presta M, Vacca A, Ria R, Giuliani R, Dell'Era P, Nico B, Roncali L, Dammacco F (1999) Human erythropoietin induces a proangiogenic phenotype in cultured endothelial cells and stimulates neovascularization in vivo. Blood 93(8):2627-2636

94. Steinlein P, Deiner E, Leutz A, Beug H (1994) Recombinant murine erythropoietin receptor expressed in avian erythroid progenitors mediates terminal erythroid differentiation in vitro. Growth Factors 10(1):1-16 